\title{
ASPECTS REGARDING THE DEVELOPMENT OF PYROTECHNIC OBSCURANT SYSTEMS FOR VISIBLE AND INFRARED PROTECTION OF MILITARY VEHICLES
}

\author{
Gheorghe Bogdan PULPEA \\ Military Technical Academy, Bucharest, Romania, \\ bogdy_203@yahoo.com
}

\begin{abstract}
During the last decades, the military combat vehicles and trucks were equipped with various weapon systems and laser rangefinders, optical devices and sighting equipment. The military vehicles were thus upgraded, so they become a more attractive target for enemy fire. Since ballistic armour cannot and will never completely protect vehicles against kinetic or explosive ammunitions, various pyrotechnic countermeasure systems such as smoke screening, were designed and implemented. Generating smoke screens or flares in the desired area (around the combat armoured vehicles) is a concern of many manufacturers of pyrotechnic protection systems, aiming to protect against detection in the visual (VIS) and infrared (IR) spectrum. The goal of this article is to present a brief state-of-theart regarding the development of pyrotechnic smoke camouflage systems and flares used to ensure countermeasures in the visible and infrared electromagnetic spectrum. Types of pyrotechnic systems and structures for the protection of military vehicles will be described briefly.
\end{abstract}

Keywords: countermeasure, cloud-screening, obscurant systems, multiple launch tubes, smoke grenade launcher

\section{Introduction}

Military combat vehicles are the most targeted objects on the battlefield. They are very useful for the military when performing different tasks with a high degree of risk. Armoured vehicles provide military protection for various threats (bullets, shells, shrapnel, fragments), offer increased mobility on the ground and assure the efficiency of a remote controlled weapon station, which enable the military to detect and fire on target. In what concerns the personal protection, it was noticed that the armour is not the safest way of defense, compared to hiding the vehicle itself from the eyeshot of the enemy.

Most missions are performed during the night, which provides a simple protection with no cost in the visual spectrum. However, this kind of protection is no longer safe once high-performance optical devices emerged, that allowed observation and firing on target in both visible (VIS) and infrared (IR) spectrum.

IR concept covers a wide range within the electromagnetic spectrum: the lower limit is the visible and the upper limit is given by the microwaves. The unaffected portions are often referred to as atmospheric transmission windows, which can be classified as follows [8]:

- Near infrared - NIR: 0,7 - $1 \mu \mathrm{m}$;

- Short-wavelength infrared - SWIR: 1 $3 \mu \mathrm{m}$;

- Mid-wavelength infrared - MWIR: 3 - 5 $\mu \mathrm{m}$;

- Long-wavelength infrared - LWIR: 8 $14 \mu \mathrm{m}$. 
To cover the whole area, the more general term "multispectral" is used.

As these optical devices are constantly upgrading, various pyrotechnic products are developed in the same time to eliminate the advantage. These are generally called countermeasure pyrotechnic systems, which by definition can be described as a measure against another measure.

A pyrotechnic system represents a set of components and is based on a pyrotechnic composition, defined as a mixture of oxidizer, fuel and binder, and a mechanical system for specific operational functions.

Currently, the utility of smoke screening is widely appreciated, being regarded as an effective countermeasure against laser or infrared detection activities. The importance of screening measures is sustained by the widespread use of thermal sensors, which are often exceeding the concealing actions. Reconsidering the purpose of screening, researchers focused on developing systems to limit the possibility of distance detection by the enemy, through infrared and laser based means.

Based on the weapon system which includes a grenade launcher, it was developed a modular launcher (multiple launch tubes), which is fixed on military vehicles.

This has led to the development of an obscuration smoke system that is based on multispectral smoke grenade which provides protection for the military vehicles by generating a smoke screen between the vehicle and the enemy. The generated smoke screen provides multispectral protection of combat vehicle against enemy detection and enables the vehicle to move away in time from the dangerous area.

\section{Definition of threat. Definition of target}

To develop a system that meets the needs on the battlefield, two essential factors that represent the input of the system design must be known:

- Threat: is the factor that triggers an attack on an object, which become a target, the first action consisting in target detection. This threat is defined by the enemy force attack that is using weapon systems and observation devices;

- Target: is the element facing the threat.

It is noticeable that, depending on the position and strength of each opponent in the battlefield, the two elements can turn from target into threat and reverse, leading to the development of threat resistant systems, making possible to switch from offensive to defensive.

Since the optoelectronic systems currently used allow observing and aiming targets in VIS and IR spectrum, the surface-to-surface and air-to-surface missiles were equipped with infrared guiding systems in order to hit targets. Thus, the main purpose of the obscurant systems is to generate an infrared screening cloud between target and threat in order to enhance the survivability of the vehicle (figure 1).

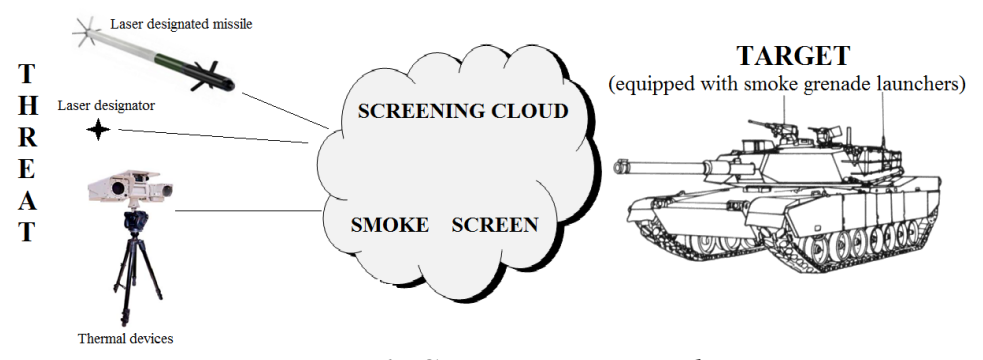

Figure 1: Screening principle

The target is characterized by overall dimensions that define the required surface coverage by the screening cloud. Military combat vehicles can be categorized as follows:
- Light vehicles: off road cars $(4 \times 4)$ with light armor;

- Heavy vehicles: also called armoured vehicles - are large sized and divide into tracked and wheeled $(4 \times 4,8 \times 8)-$ tanks, armored personnel carriers, trucks of 
Table 1 Military vehicles equipped with obscurant system

\begin{tabular}{|l|l|}
\hline Off road cars (4x4) & -Highly Mobile Multipurpose Wheeled Vehicle \\
(HMMWV) - Humvee (SUA); & Size: 4,5 m x 3,3m x 2,16m (L-W-H); \\
- High Mobility Tactical Vehicle VAMTAC \\
(Vehículo de AltaMovilidad Táctico-Spania); \\
Size: 4,84m x 2,17m x 1,9m (L-W-H); \\
Smoke system: M7 (LVOSS) Light Vehicle \\
Obscuration Smoke System; Rheinmetall -40mm \\
Rapid Obscurant System (ROSY);
\end{tabular}

Obscurant systems can be installed both independently and along other weapons as additional equipment on all military vehicles, with an installation kit. Note that countermeasure pyrotechnic systems are integral parts of the protection system of a military vehicle.

Combat scenarios that may involve military combat vehicles are varied, so obscurant systems must be adapted in order to respond to any situation and to protect the crew. The main objective of this countermeasure systems are reducing the effectiveness of enemy's modern optoelectronic systems by obstructing their visual field for a period of time required for the execution of military actions such as: 
- Rescue and evacuation of a downed crew;

- Withdraw from the enemy firing area (figure 2.a);
- Safe crossing of open areas under enemy surveillance (figure $2 \mathrm{~b}$ );

- Creating conditions for surprising the enemy, creating a diversion.

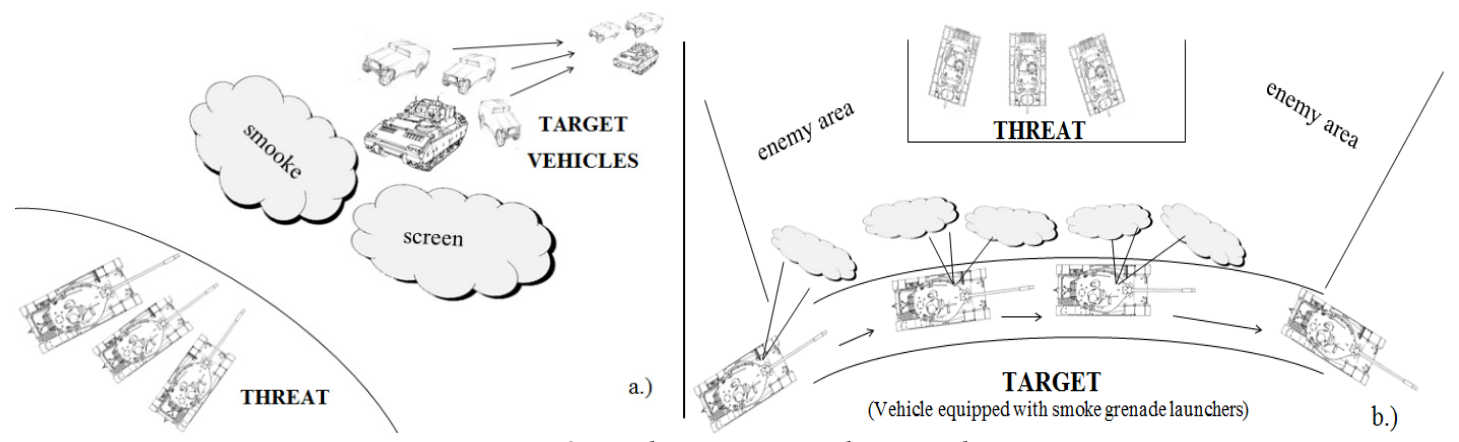

Figure 2: Military tactical procedures

3. Realizing and organizing the Generally, a pyrotechnic obscurant system countermeasure systems consists of two main components: a smoke Creating, organizing and installing the smoke grenade launcher on the vehicle represent the elements that describe a pyrotechnic countermeasure system and determine its proper functioning. grenade launch facility and a payload (smoke grenades). The launch facility (figure 3 ) is also composed of two assemblies: the launcher and the control panel.

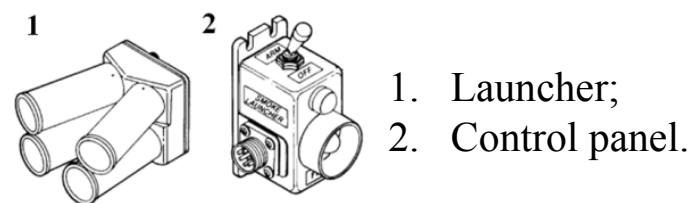

Figure 3: Launcher facility

Usually launchers are grouped in sets of two or more interconnected tubes that are installed on the vehicle through an interface

(fixing plate), adapted for each vehicle (figure 4).

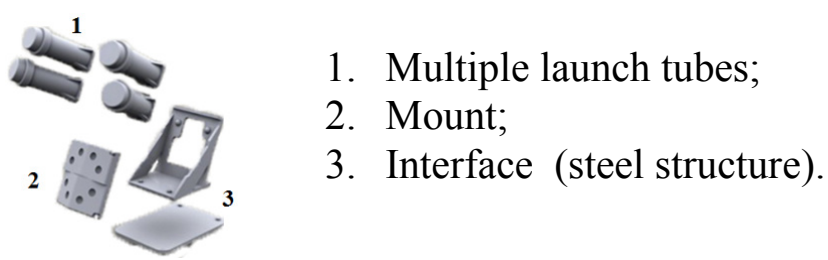

Figure 4: Launcher configuration

The mount provides electrical contact for electric initiation of grenades and is connected via the control box, located inside the vehicle at the commander station. The control box allows launching one grenade at a time or in salvo. Tubes can be independent or combined (figure 5). In the case of independent tubes, the electrical contact is built inside the tube and the connection between them is directly through the fixing plate and can have different configurations (figure 6). These options are usually installed on the tank turret, because they require greater gripping surface. 


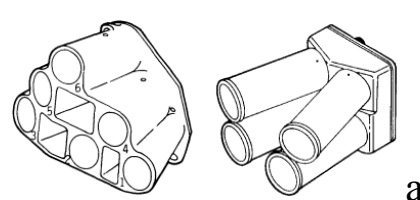

a)

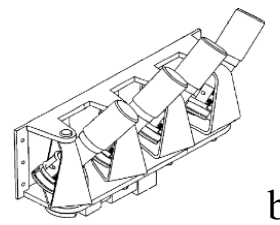

b)

Figure 5: a) combined launcher, b) independent launcher [3] [4] [5]
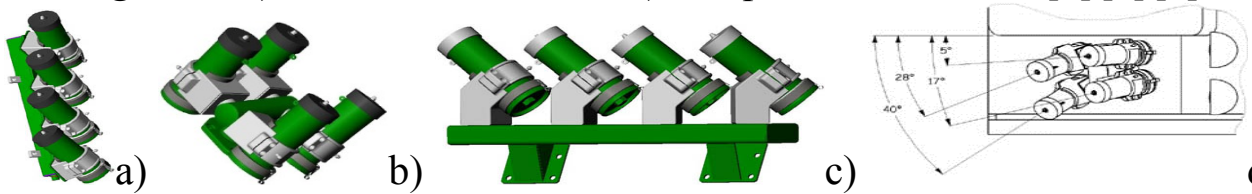

c)

d)

Figure 6: a) vertical configuration, b) "clustered" configuration,

c) "rail mounted" configuration, d) azimuth angles [5]

The fixing plates are steel structures, welded to the contact surface with a specific orientation (different angles between tubes - figure 6.d) which allows a good distribution in space of the smoke screen. The payload has to generate a smoke screen in a field of $120^{\circ}-140^{\circ}$ degrees opening, at a distance of $30-40 \mathrm{~m}$ from the vehicle to a depth of 10-30 $\mathrm{m}$ and a height of 6-20 m (figure 7) [1]. These values are determined particularly by the placement of the launch tubes.

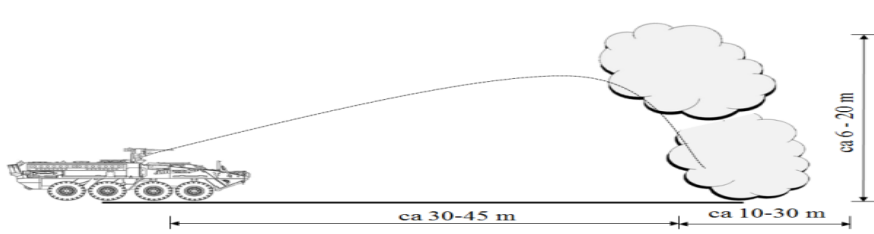

Figure 7: Smoke dispersion

Usually launchers are mounted on either side of the turret (one discharger on the right-hand side and another one on the lefthand side - see figures 8.a, 9) or multiple launchers are mounted on the remote weapon system. In this case the system firing front is the same with the weapon. For vehicles without a gun turret, launchers are positioned on all sides of the vehicle's roof, based on the free space, and allow a $360^{\circ}$ degrees coverage. This configuration is most suitable for small caliber launchers (4 tubes) and usually consists of 4 up to 6 launchers (figures 8.b, 9). Other configurations require a single $360^{\circ}$ degrees coverage launcher that is positioned independently on the rotating platform, being remotely controlled from inside the vehicle (fig 10).

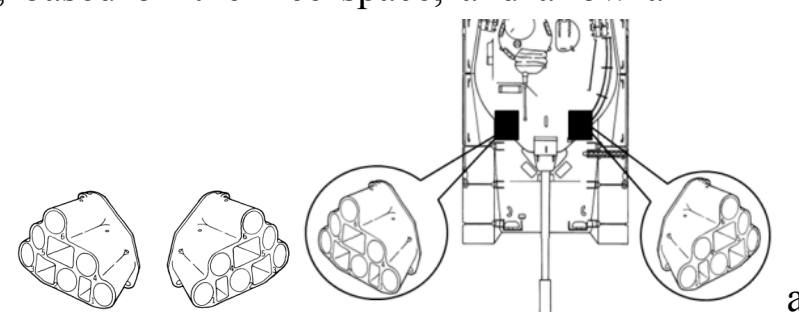

a)

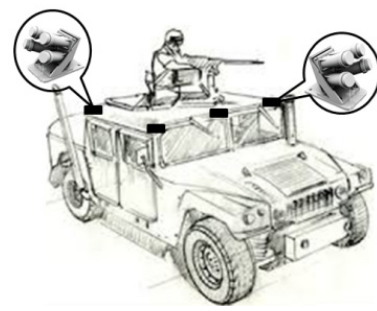

Figure 8: Possible mounting configurations of the launchers

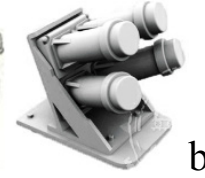

b)

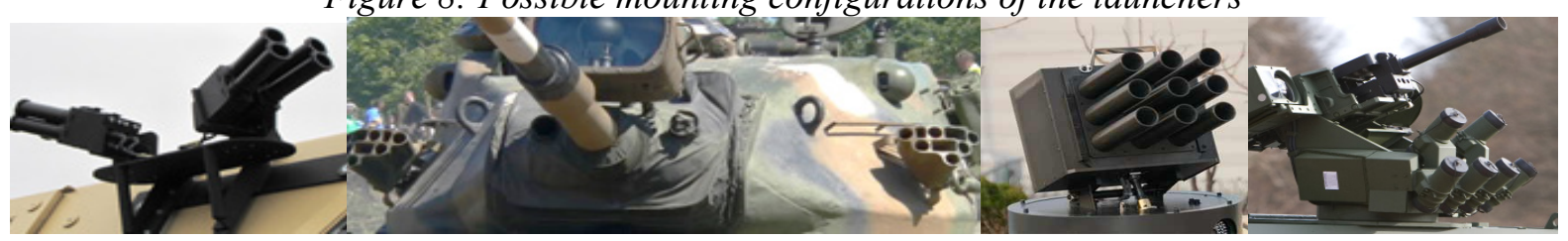

Figure 9: Location of launchers on the vehiclThe dificulty of using the obscurant systems comes from the need of manual loading, which forces the military to get discovered. 


\section{Design variations}

The countermeasure pyrotechnic systems vary on each manufacturer, and are in a continuous development. Depending on the market requirements and types of military vehicles, these systems have been developed for various calibres like $40 \mathrm{~mm}$, 66 $\mathrm{mm}, 76 \mathrm{~mm}, 80 \mathrm{~mm}$ (table 1) [3], [4], [5].

Table 1 Constructive version

\begin{tabular}{|c|c|}
\hline 76 mm grenade Launchers & $\begin{array}{l}\text { Light Vehicle Obscurant } \\
\text { Smoke System (LVOSS)-M7 } \\
\text { (cal. } 66 \mathrm{~mm})\end{array}$ \\
\hline $\begin{array}{l}\text { M6 Countermeasure } \\
\text { Discharger (cal. } 66 \mathrm{~mm} \text { ) }\end{array}$ & $\begin{array}{ll} & \text { M243/M257/M259 } \\
\text { Smoke Grenade } \\
1,7_{3}^{4} \\
\text { Launchers }\end{array}$ \\
\hline $\begin{array}{l}\text {-4 tube smoke grenade discharger } \\
\text {-provides up to } 360^{\circ} \text { screening coverage }\end{array}$ & -4 and 8 tube smoke grenade discharger \\
\hline $\begin{array}{l}\text { M250 } \\
\text { Smoke Grenade } \\
\text { Launchers }\end{array}$ & 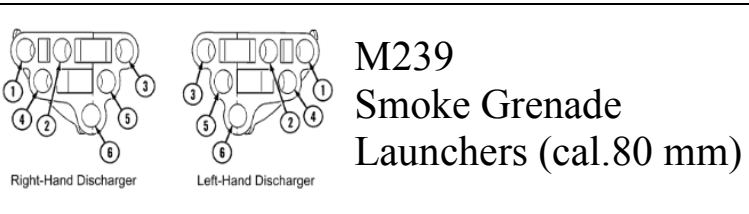 \\
\hline $\begin{array}{l}\text { Rheinmetall's } 40 \mathrm{~mm} \\
\text { Rapid Obscurant System } \\
\text { (ROSY) }\end{array}$ & $\begin{array}{l}40 \mathrm{~mm} \text { WEGMAN- } \\
\text { protection system }\end{array}$ \\
\hline $\begin{array}{l}\text {-rapid, large obscurance, } 360^{\circ} \text { degrees cover; } \\
\text {-effective during movement; } \\
\text {-multispectral effectiveness; } \\
\text {-independent on terrain and environment }\end{array}$ & $\begin{array}{l}\text {-possibility of independent use; } \\
\text {-use within a modern weapon station; } \\
\text {-protection of buildings/objects; } \\
\text {-camp defense. }\end{array}$ \\
\hline
\end{tabular}

\section{Conclusions}

Throughout the summarised information, this article highlights the need of countermeasure systems and their effectivness on the battlefield, as witnessed by the increasing number of models and design solutions emmerging on the international market.

\section{References}

[1] Goga Doru-Adrian, Pirotehnie, principii de bază şi aplicaţii, Editura ATM, Bucureşti;

[2] IMDS Corporation 1-01-1002, Defense Systems M6 Countermeasure;

[3] Gary`s Combat Vehicle Reference Guide U.S., Vehicle Grenade Launchers;

[4] Non-Lethal Weapons Program, U.S. Departement of Defence;

[5] Wegmann USA, Inc. VA 24502 USA 1-434-385-1580, 76 mm Grenade Launchers;

[6] United States Patent nr. 4726295 Feb.23,1988, Grenade arrangement for screening cloud;

[7] United States Patent Application Publication nr. US2001/0015126 A1 Aug.23,2001, Multiple-barrel mortar assembly for launching grenades off the side of a combat vehicle;

[8] Ţurcanu Eugen Daniel, Teză de Doctorat-Contribuţii la analiza de sistem a echipamentelor pe bază de termoviziune, Bucureşti 2009;

[9] OPFOR, Worldwide equipment guide. 